Tahun 2020

\title{
LATIHAN KOLABORATIF DALAM MENINGKATKAN KEMAMPUAN TEKNIK DASAR BERMAIN SEPAKBOLA SISWA
}

\author{
Oleh: Rury Rizhardi, M.Pd \\ (Universitas PGRI Palembang) \\ ruryrizhardi@univpgri-palembang.ac.id
}

\begin{abstract}
Abstrak
Penelitian ini bertujuan untuk mengetahui apakah latihan kolaboratif mampu meningkatkan kemampuan teknik dasar bermain sepakbola. Metode Penelitian yang digunakan adalah pre-experimental dengan desain pretest-posttest only control group design. Subjek Penelitian ini adalah siswa ekstrakurikuler SMK Negeri 7 Palembang yang terdiri dari 26 siswa. Instrumen Penelitian ini terdiri dari tes kemampuan teknik dasar bermain sepakbola berupa passing, dribbling, dan shooting. Data dianalisis menggunakan uji independent sample t-test. Hasil Penelitian menunjukkan bahwa nilai $t_{\text {hitung }}=$ $10,73>t_{\text {tabel }}=2,06$ berarti $H_{0}$ ditolak. Dengan demikian dapat disimpulkan bahwa latihan kolaboratif mampu meningkatkan kemampuan teknik dasar bermain sepakbola di SMK Negeri 7 Palembang.
\end{abstract}

Kata Kunci : Latihan Kolaboratif, Kemampuan Teknik Dasar Bermain Sepakbola

\section{COLLABORATIVE EXERCISE IN IMPROVING THE BASIC ABILITY OF STUDENTS 'FOOTBALL PLAYING TECHNIQUES}

\begin{abstract}
This researchaims to determine whether collaborative training can improve the basic technical skills of playing football. The research method used was a pre-experimental design with a pretest-posttest only control group design. The subjects of this research were extracurricular students of SMK Negeri 7 Palembang consisting of 26 students. This research instrument consisted of a test of basic technical ability to play football in the form of passing, dribbling, and shooting. Data were analyzed using independent sample t-test. The results showed that the value of $t_{-}$count $=10.73>t_{-}$table $=2.06$ means that $H_{0}$ was rejected. It can be concluded that the collaborative exercise is able to improve the basic techniques of playing football at SMK Negeri 7 Palembang.
\end{abstract}

Keywords: Collaborative Training, Basic Technical Skills in Playing Soccer

Correspondence author: Rury Rizhardi, Universitas PGRI Palembang, Indonesia. E-Mail: ruryrizhardi@univpgripalembang.ac.id

cc) (†) (?)

Jurnal HalamanOlahraga Nusantara licensed under a Creative Commons Attribution-ShareAlike 4.0 International License. 


\section{PENDAHULUAN}

Faktor yang menyebabkan keberhasilan dalam permainan sepakbola adalah teknik dasar. Teknik dasar adalah semua kegiatan yang mendasari dalam bermain sepakbola yang berupa gerakan-gerakan, baik gerakan yang dilakukan tanpa bola maupun dengan bola (Sukatamsi dalam Atiq, 2012) Akan tetapi, teknik dasar siswa dalam bermain sepakbola tergolong rendah.

Berdasarkan hasil observasi di SMK Negeri 7 Palembang, kemampuan teknik dasar siswa masih tergolong rendah dikarenakan belum adanya program latihan yang terstruktur dengan baik, hal ini terlihat kemampuan passing siswa masih banyak yang belum tepat sasaran, kemampuan dribbling siswa masih kurang pada saat bermain bola dengan mudah direbut oleh lawan, kemampuan shooting siswa masih banyak yang belum tepat sasaran dikarenakan kurangnya latihan. Kemudian dari aspek sarana di sekolah tersebut masih kurang memadai seperti jaring gawang yang rusak dan terdapat siswa yang belum memakai perlengkapan seperti sepatu. Dan pelatih yang belum memiliki lisensi kepelatihan sehingga mengakibatkan program latihan di SMK Negeri 7 Palembang tidak terstruktur dan terencana.

Keberhasilan dari suatu proses belajar mengajar ditentukan oleh banyak faktor seperti guru/pelatih, program latihan, sarana dan prasarana, dan situasi dalam proses latihan (Nurhadi dalam Tri Yoga Saputra, I Nyoman Kanca, 2017). Oleh karena itu, guru/pelatih harus mampu menciptakan program latihan yang dapat meningkatkan kemampuan siswa. Salah satunya dengan memilih program latihan yang tepat. Berdasarkan permasalahan tersebut, diperlukan latihan yang dapat meningkatkan kemampuan teknik dasar siswa dalam bermain sepakbola sesuai dengan situasi dan kondisi yang ada. Latihan yang dapat meningkatkan kemampuan teknik dasar bermain sepakbola adalah latihan kolaboratif.

Menurut (Mutohir dalam Rohim, 2014) latihan kolaboratif menekankan pada kreatifitas penumbuhan kondisi latihan yang kondusif melalui penerapan program latihan yang di sesuaikan dengan situasi (lingkungan) tertentu. Latihan kolaboratif tidak menunjuk salah satu program latihan tertentu, namun menunjuk pada berbagai keterampilan latihan yang di adaptasikan secara tepat oleh pelatih dalam proses pelaksanaan latihan. Selanjutnya (Rohim, 2014) menjelaskan bahwa latihan 
kolaboratif adalah pemilihan latihan yang sesuai dengan kondisi dan situasi lingkungan.

(Wiarto, 2015) menjelaskan bahwa latihan kolaboratif lebih banyak memberikan dampak yang positif terhadap siswa ekstrakurikuler seperti siswa lebih cenderung berlatih lebih banyak tentang materi ajar dan mengingatnya lebih lama dibandingkan jika materi ajar tersebut dihadirkan dalam bentuk lain.

Arikunto et al. dalam (Munandar, H., Suwardi, 2018) menjelaskan bahwa dalam Penelitian kolaboratif, pihak yang melakukan tindakan adalah pelatih itu sendiri, sedangkan yang diminta melakukan pengamatan terhadap berlangsungnya proses tindakan adalah peneliti, bukan guru yang sedang melakukan tindakan.

Berdasarkan beberapa definisi diatas, maka dapat disimpulkan bahwa latihan kolaboratif adalah latihan yang disesuaikan dengan situasi dan kondisi lingkungan peserta didik agar terjadi latihan yang bermakna.

Teknik dasar adalah semua kegiatan yang mendasari permainan sepakbola yang dilakukan dengan gerakan-gerakan, baik gerakan yang dilakukan tanpa bola maupun dengan bola (Sukatamsi dalam Atiq, 2012). Latihan untuk meningkatkan teknik dasar bermain sepakbola dilakukan drill mengenai cara menendang, mengumpan, mengontrol atau menghentikan bola, menggiring bola, menyundul bola, dan lainnya. (Herwin dalam Andrianto, 2015) menyebutkan teknik dengan bola meliputi penguasaan bola dengan bagian tubuh menggunakan perasaan (ball feeling), mengumpan bola (passing), menendang bola ke arah gawang (shooting), menggiring bola (dribbling), menerima dan menguasai bola (receiving and controlling the ball), menyundul bola (heading), gerak tipu (feinting), penjaga gawang (goalkeeping).

Dari uraian diatas, maka dapat disimpulkan bahwa kemampuan teknik dasar bermain sepakbola adalah kemampuan dasar yang harus dimiliki siswa saat bermain sepakbola baik gerakan dengan bola atau tanpa bola. Selanjutnya kemampuan teknik dasar yang digunakan dalam Penelitian ini adalah passing, dribbling, dan shooting. 
Tujuan Penelitian ini adalah untuk mengetahui apakah latihan kolaboratif dalam meningkatkan kemampuan teknik dasar bermain sepakbola di SMK Negeri 7 Palembang.

\section{METODE}

Penelitian ini merupakan Penelitian eksperimen dengan tipe pre-experimental. Desain yang digunakan adalah pretest-posttest group design. Secara singkat, desain tersebut dapat digambarkan sebagai berikut.

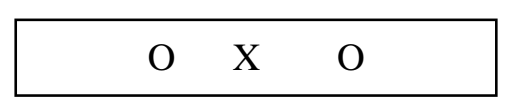

Gambar 1:Pretest-Posttest Group (Arikunto, 2013)

Keterangan:

$\mathrm{X}=$ Treatment dengan latihan kolaboratif (Variabel bebas)

$\mathrm{O}=$ Pretest/Posttest (Variabel terikat)

Subjek Penelitian ini adalah siswa ekstrakurikuler yang berjumlah 26 siswa laki-laki. Pemilihan subjek dilakukan berdasarkan gender agar lebih mudah melatihnya.

\section{HASIL DAN PEMBAHASAN}

Data kemampuan teknik dasar bermain sepakbola berupa passing, dribbling, dan shooting siswa diperoleh dari hasil pretest dan posttest. Dimana pretest tersebut dilaksanakan sebelum siswa diberikan perlakuan. Sedangkan postest dilaksanakan setelah siswa diberikan perlakuan. Adapun data hasil rata-rata nilai pretest dan posttest dapat dilihat pada tabel 4.1 adalah sebagai berikut.

Tabel 1

Rata-Rata Nilai Pretest dan Posttest Tes Kemampuan Teknik Dasar Bermain Sepakbola

\begin{tabular}{c|c}
\hline Tes & Rata-Rata Nilai Tes \\
\hline Pretest & $\mathbf{7 5 , 3 3}$ \\
\hline Posttest & $\mathbf{8 2 , 8 5}$ \\
\hline
\end{tabular}




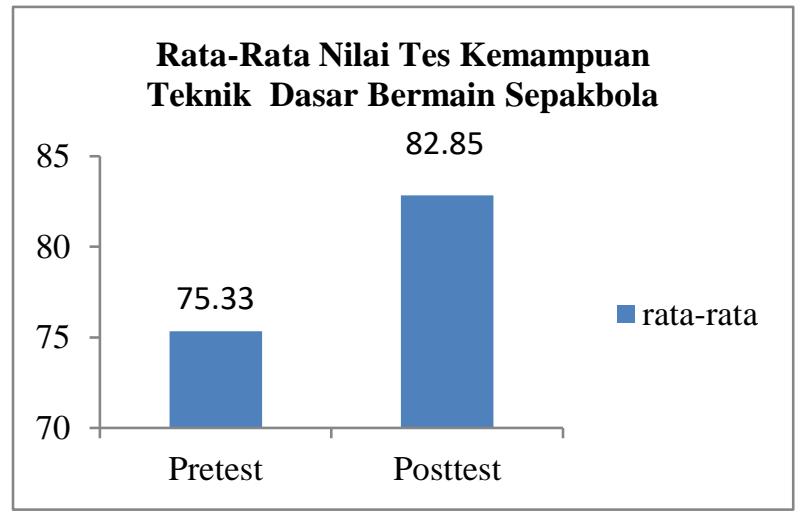

Gambar 2. Diagram Nilai Rata-Rata Kemampuan Teknik Dasar Bermain Sepakbola

Dari tabel 1 terlihat bahwa rata-rata nilai tes kemampuan teknik dasar bermain sepakbola siswa pada saat sebelum dan setelah diberikan perlakuan terdapat perbedaan, dimana nilai rata-rata pretest siswa sebesar 75,33 sedangkan nilai ratarata posttest siswa sebesar 82,85 .

Untuk mengetahui tingkat kemampuan teknik dasar bermain sepakbola siswa berdasarkan keterampilan passing, dribbling, dan shooting berikut ini ditampilkan pada tabel 2 .

Tabel 2

Nilai Rata-Rata Presentase Skor Passing, Dribbling, Shooting

\begin{tabular}{cccc}
\hline No & Keterampilan & Pretest & Posttest \\
\hline 1 & Passing & 76,38 & 81,65 \\
\hline 2 & Dribbling & 74,85 & 81,23 \\
\hline 3 & Shooting & 63,46 & 73,23 \\
\hline & Rata-Rata & $\mathbf{7 1 , 5 6}$ & $\mathbf{7 8 , 7 1}$ \\
\hline
\end{tabular}

Dari tabel 2 diketahui bahwa kemampuan teknik dasar bermain sepakbola yang diuji dalam Penelitian ini ada 3 keterampilan yaitu passing, dribbling, dan shooting. Hasil dari tes keterampilan tersebut menunjukkan bahwa terdapat perbedaan untuk masing-masing keterampilan kemampuan teknik dasar bermain sepakbola.

Passing, berdasarkan hasil tes keterampilan menunjukkan bahwa terdapat perbedaan yang cukup jauh yaitu nilai rata-rata pretest siswa sebesar 76,38 sedangkan nilai rata-rata posttest siswa sebesar 81,65 dikarenakan siswa sudah mampu untuk melakukan gerakan passing yang baik. 
Dribbling, berdasarkan hasil tes keterampilan menunjukkan bahwa terdapat perbedaan yang cukup jauh yaitu nilai rata-rata pretest siswa sebesar 74,85 sedangkan nilai rata-rata posttest siswa sebesar 81,23 dikarenakan siswa sudah mampu mengendalikan bola dengan baik sehingga bola tidak mudah direbut oleh lawan dan lepas dari kontrol.

Shooting, berdasarkan hasil tes keterampilan menunjukkan bahwa terdapat perbedaan yang cukup jauh yaitu nilai rata-rata pretest siswa sebesar 63,46 sedangkan nilai rata-rata posttest siswa sebesar 73,23 dikarenakan siswa sudah mampu melakukan shooting tepat sasaran ke gawang.

Berdasarkan penjelasan hasil tes kemampuan teknik dasar bermain sepakbola untuk masing-masing keterampilan diatas secara keseluruhan disimpulkan bahwa nilai rata-rata posttest untuk masing-masing kemampuan teknik dasar bermain sepakbola setelah diberikan latihan kolaboratif lebih baik daripada nilai rata-rata pretest sebelum diberikan latihan kolaboratif. Oleh karena itu, latihan kolaboratif mampu meningkatkan kemampuan teknik dasar bermain sepakbola di SMK Negeri 7 Palembang.

\section{Analisis Data Hasil Penelitian}

Berdasarkan data hasil Penelitian diperoleh nilai rata-rata pretest sebesar 75,33 sedangkan nilai rata-rata posttest sebesar 82,85 . Dari nilai rata-rata tersebut menunjukkan bahwa $\mu_{1}>\mu_{2}$ yang berarti latihan kolaboratif mampu meningkatkan kemampuan teknik dasar bermain sepakbola di SMK Negeri 7 Palembang. Dalam Penelitian ini menggunakan teknik analisis data independent sample t-test untuk menguji generalisasi (signifikan) hasil Penelitian berupa perbandingan nilai pretest dan posttest. Adapun hasil perhitungan uji-t dapat dilihat sebagai berikut.

Tabel 3

Hasil Perhitungan Uji-t

\begin{tabular}{ccccc}
\hline Subjek & Pretest & Posttest & Gain $(\mathbf{d})$ & $\mathbf{d}^{\wedge} \mathbf{2}$ \\
\hline 1 & 78,25 & 84,91 & 6,66 & 44,36 \\
\hline 2 & 76,14 & 88,77 & 12,63 & 159,52 \\
\hline 3 & 75,44 & 84,56 & 9,12 & 83,17 \\
\hline 4 & 76,49 & 81,40 & 4,91 & 24,11 \\
\hline 5 & 75,79 & 82,81 & 7,02 & 49,28 \\
\hline 6 & 70,53 & 82,11 & 11,58 & 134,10 \\
\hline
\end{tabular}




\begin{tabular}{ccccc}
\hline 7 & 70,18 & 82,11 & 11,93 & 142,32 \\
\hline 8 & 76,84 & 83,51 & 6,67 & 44,49 \\
\hline 9 & 76,49 & 81,75 & 5,26 & 27,67 \\
\hline 10 & 77,19 & 80,35 & 3,16 & 9,99 \\
\hline 12 & 70,18 & 82,11 & 11,93 & 142,32 \\
\hline 13 & 78,95 & 82,81 & 3,86 & 14,90 \\
\hline 14 & 71,23 & 83,16 & 11,93 & 142,32 \\
\hline 15 & 78,25 & 80,00 & 1,75 & 3,06 \\
\hline 16 & 75,79 & 88,42 & 12,63 & 159,52 \\
\hline 17 & 70,18 & 82,81 & 12,63 & 159,52 \\
\hline 18 & 76,84 & 81,05 & 4,21 & 17,72 \\
\hline 19 & 77,19 & 81,75 & 4,56 & 20,79 \\
\hline 20 & 78,60 & 83,51 & 4,91 & 24,11 \\
\hline 21 & 74,74 & 83,16 & 8,42 & 70,90 \\
\hline 22 & 71,23 & 80,70 & 9,47 & 89,68 \\
\hline 23 & 77,54 & 83,86 & 6,32 & 39,94 \\
\hline 24 & 79,30 & 82,81 & 3,51 & 12,32 \\
\hline 25 & 70,18 & 81,40 & 11,22 & 125,89 \\
\hline 26 & 79,30 & 82,46 & 3,16 & 9,99 \\
\hline Jumlah & $\mathbf{7 5 , 7 9}$ & 81,75 & 5,96 & 35,52 \\
\hline Rata-rata & $\mathbf{7 5 , 3 3}$ & $\mathbf{2 1 5 4 , 0 4}$ & $\mathbf{1 9 5 , 4 1}$ & $\mathbf{1 7 8 7 , 5 1}$ \\
\hline & & & \\
\hline
\end{tabular}

$$
\begin{gathered}
M d=\frac{\sum d}{N}=\frac{195,41}{26}=7,52 \\
\sum \mathrm{x}^{2} \mathrm{~d}=\sum \mathrm{d}^{2}-\frac{\left(\sum \mathrm{d}\right)^{2}}{\mathrm{~N}} \\
\sum \mathrm{x}^{2} \mathrm{~d}=1787,51-\frac{(195,41)^{2}}{26} \\
\sum \mathrm{x}^{2} \mathrm{~d}=1787,51-\frac{38185,0681}{26} \\
\sum \mathrm{x}^{2} \mathrm{~d}=1787,51-1468,66 \\
\sum=\frac{M d}{\sqrt{\frac{\sum x^{2} d}{N(N-1)}}}=\frac{7,52}{\sqrt{\frac{318,85}{26(26-1)}}}=10,73
\end{gathered}
$$

Berdasarkan hasil perhitungan uji-t diatas, maka diperoleh nilai $t_{\text {hitung }}=$ $10,73>t_{\text {tabel }}=2,06$ artinya signifikan. Sehingga dapat disimpulkan bahwa latihan kolaboratif mampu meningkatkan kemampuan teknik dasar bermain sepakbola di SMK Negeri 7 Palembang. 


\section{KESIMPULAN}

Berdasarkan hasil Penelitian yang telah dikemukakan, dapat disimpulkan bahwa latihan kolaboratif dalam meningkatkan kemampuan teknik dasar bermain sepakbola di SMK Negeri 7 Palembang.

Adapun saran peneliti terkait dengan Penelitian yaitu (1) pelatih hendaknya dapat menjadikan latihan kolaboratif sebagai salah satu alternatif metode dalam melatih untuk meningkatkan kemampuan teknik dasar bermain sepakbola siswa agar lebih baik lagi. Pelatih dan siswa diharapkan dapat bekerja sama agar latihan ini dapat berjalan maksimal selama proses latihan berlangsung; (2) sekolah hendaknya dapat menjadikan latihan kolaboratif sebagai bahan dan pertimbangan untuk menentukan kebijakan dalam rangka meningkatkan mutu dan kualitas pendidikan.

\section{DAFTAR PUSTAKA}

Andrianto, J. R. (2014). Pengembangan Model Latihan Teknik Dasar Ball Feeling Sepakbola Menggunakan Media Pembelajaran Audio Visual Pada Siswa Usia 11 Tahun Sekolah Sepakbola Sanggar Kegiatan Belajar (SSB SKB) Gudo Kabupaten Jombang . Bravo's Jurnal Volume 2 No. 3, 89-97.

Arikunto, S. (2014). Prosedur Penelitian. Jakarta: Bumi Aksara.

Atiq, A. (2012). Tingkat Keterampilan Teknik Dasar Sepakbola LPI SMP 3 Pontianak . Jurnal Media Ilmu Keolahragaan Indonesia Volume 2 Edisi 1, 34-36.

Munandar, H., Suwardi, \& Hasyim. (2018). Upaya Meningkatkan Hasil Belajar Menggiring Bola Dalam Permainan Sepakbola Melalui Model Kolaborasi Murid Kelas V B SD Inpres 167 Mattoanging Kecamatan Turatea Kabupaten Jene Ponto. Jurnal Universitas Makassar, 1-15.

Putra, I. K., Kanca, I. N., \& Wijaya, I. M. (2014). Implementasi Pembelajaran Kooperatif NHT Untuk Meningkatkan Aktivitas dan Hasil Belajar Teknik Dasar Passing Sepakbola. e-Journal Pendidikan Jasmani Kesehatan dan Rekreasi Volume 1, 1-11.

Rohim. (2014). Latihan Kolaborasi Pada Pelajaran Penjaskes Dapat Menumbuhkan Kreativitas dan Minat Siswa. HUMANIS Volume 6 No. 2, 147-154.

Wiarto, G. (2015). Inovasi Pembelajaran dalam Pendidikan Jasmani. Yogyakarta: Laksitas. 